\title{
CRÍTICA AO MODELO DA NOVA SOCIEDADE CIVIL
}

ADRIÁN GURZA LAVALLE*

Numa bela lição de sabedoria cínica, o arguto Diógenes andou pelas ruas, lanterna na mão, em pleno dia e sob uma luz rutilante, em busca de um homem honesto - segundo diz a antiga estória a ele atribuída, na qual mostra-se de forma eloqüente a crítica do filósofo à vanglória e ao egoísmo humano. No extremo oposto desse "pessimismo", o pensamento que gravita na órbita das esquerdas vive a encontrar agentes e sujeitos de moral elevada, portadores de interesses universais que encarnam a esperança de um mundo justo - arquitetado ora mediante transformações radicais, ora mediante vagarosas tendências de ampliação da democracia. Ante a lanterna "otimista" desse pensamento, mais um "homem honesto" teria se sedimentado no decorrer das últimas décadas: a nova sociedade civil.

Porém, nem quanto ao sentido e às caraterísticas de seu agir e sequer quanto a suas consequiências é possível afirmar a existência de uma unidade óbvia no universo de práticas de ação coletiva que soem ser abarcadas na nova sociedade civil. Por isso, é digno de espanto se deparar com amplo consenso no que diz respeito aos atributos que a definem: diversa, plural, ubíqua e representante do interesse geral - a cuja incessante atividade é inerente um ímpeto democratizador. Na América Latina e particularmente no Brasil a leitura de matriz sociológica dos últimos lustros tem sido realizada a partir de tal consenso, isto é, através da mira analítica - ou pressupostos lógicos - das teorizações mais influentes sobre a sociedade civil. De fato, o

\footnotetext{
* Agradeço as acertadas sugestões e a diligente correção de estilo do amigo Joaci Pereira Furtado.
} 
extraordinário sucesso dos modelos teóricos responsáveis pela redescoberta da sociedade civil extravasou o mundo acadêmico e conquistou um lugar privilegiado na linguagem da mídia, fazendo com que o termo "sociedade civil" se aproxime mais de um lugar comum do que de um problema que precisa ser tematizado empírica e teoricamente. Nesse sentido, o intuito do presente artigo é retornar aos fundamentos, cuja precária solidez no caso do modelo da nova sociedade civil tem sido escamoteada indiretamente tanto pelas boas intenções do otimismo, avesso a deixar a esperança sem corpoquer dizer, sem sujeito ou sem agente coletivo - , quanto pelos efeitos do sucesso, sempre atraente e influente sobre aqueles que têm de optar entre diferentes estratégias analíticas. Para tanto, na primeira parte será trazida à tona a inveterada tradição de argumentos sobre a sociedade civil, mostrando, na segunda parte, as infelizes conseqüências da ruptura que o modelo da nova sociedade civil introduz com respeito a essa tradição.

\section{HERÁLDICA DA SOCIEDADE COM ESTADO LEGÍTIMO}

O estado robusto e dinâmico de uma sociedade civil, que alastra seus efeitos salutares sobre o conjunto da sociedade, não é um fenômeno isento de controvérsia sequer nos Estados Unidos — país de uma lendária tradição de consociação cujo vigor causara espanto a Tocqueville. Segundo o conceituado diagnóstico de Robert D. Putnam, exposto com efeitos de estardalhaço no seu artigo "Bowling Alone"1, esse espírito plurissecular de comunidade cívica teria sido fortemente abalado desde a década de $60 \mathrm{e}$ após quarenta anos pareceria apresentar uma franca erosão. De forma paradoxal, enquanto Putnam alegoriza a falência da cultura associativa cívica norte-americana na figura de uma sociedade onde apenas é possível jogar boliche sozinho, a literatura dominante do modelo da nova sociedade civil e os especialistas na área falam, para o mesmo período, do auge do associativismo civil, do renascimento, ressurreição, reconstrução ou revival da sociedade civil e de suas conseqüências democratizadoras. ${ }^{2}$

1 Robert D. Putnam, "Bowling alone: America's declining social capital". Journal of Democracy, pp.65-78.

2 Cf. v. gr. Jean Cohen e Andrew Arato, Civil society and political theory. pp. 29-82; e, para caso do Brasil, Leonardo Avritzer, "Um desenho institucional para o novo associativismo". Lua Nova, 39, 1997, pp. 149-174, particularmente pp. 161-168; e Sergio Costa, "Contexto da construção do espaço público no Brasil". Novos Estudos, 47, 1997, pp. 179-182, particularmente pp. 183-192. 
Na verdade, existe uma longa tradição de conceituações e interpretações já consagradas sobre a sociedade civil, cuja história perpassa a obra de autores da envergadura de Hobbes, Locke, Ferguson, Paine, Kant, Hegel, Montesquieu, Rousseau, Tocqueville e Marx. ${ }^{3}$ A leitura da nova vitalidade da sociedade civil, todavia, não se insere propriamente como continuação da perspectiva analítica de qualquer um desses grandes pensadores, e embora seu pertencimento de origem remeta ao marxismo, tratase de uma nova reformulação francamente distanciada de seus predecessores. Alguns dos traços gerais que definem esse distanciamento, isto é, alguns dos elementos constitutivos do modelo, deveriam resultar polêmicos - para dizer o mínimo - e, no entanto, as teses da nova sociedade civil têm recebido surpreendente aceitação nos meios acadêmico, político e até na mídia. ${ }^{4}$

As formulações conceituais sobre a sociedade civil foram, por via de regra, um ponto obrigatório no itinerário das teorias orientadas a elaborar a relação entre o Estado e a sociedade 5 - mais especificamente, dentro daqueles corpora teóricos que preservavam um lugar privilegiado para refletir a especificidade dessa relação a partir dos efeitos que, em ambos os pólos, introduzia tanto a dinâmica autônoma dos interesses privados desenvolvidos no bojo da própria sociedade quanto a possibilidade de sua consociação harmônica ou conflitante. Com efeito, em função do papel e dos alcances reservados nesses corpora à consociação civil, no que diz respeito a seu vínculo com o Estado, configura-se mais de uma "família de argumentos da sociedade civil" 6 — nas quais ela aparece definida ora

30 estudo mais abrangente sobre as transformaçōes da idéia de sociedade civil encontra-se no instigante trabalho de Jean Cohen e Andrew Arato, cf. op. cit., particularmente pp. 83-176; cf. também Norberto Bobbio. Estado, gobierno y sociedad - Por una teoría general de la política. Pp. 39-67.

4 As causas disso serão analisadas mais adiante.

5 Não é fortuito que as formulações teóricas da sociedade civil tenham se desenvolvido de forma paralela à problemática radicalmente moderna dos fundamentos legítimos do poder, isto é, das teorias da legitimidade. Hegel, em sua Filosofia do Direito, refere-se ao caráter especificamente moderno da legitimidade da seguinte forma: "Aquilo que tem de valer agora não vale mais pela mediação do poder, vale pouco pela mediação do hábito e dos costumes, mas sobretudo pela mediação da inteligência e do fundamento" (...) "O princípio do mundo moderno exige que tudo aquilo que tem de ser reconhecido por todo homem lhe apareça como algo legítimo". Citado por Jürgen Habermas, História y crítica de la opinión pública - La iransformación estructural de la vida pública. p. 150. (Neste caso e ao longo do artigo a tradução dos textos do castelhano ou do inglês para o português é nossa).

${ }^{6}$ A expressão "famílias de argumentos da sociedade civil" provem de Michael W. Foley e Bob Edwards, "La paradoja de la sociedad civil". Este País, pp. 2-10. No artigo trabalha-se com 
como identidade, ora como momento, ora como coadjuvante ou como essência do Estado. Nesses termos, a influente literatura que alimenta as análises sobre o renascimento da sociedade civil atribuir-se-ia pujança suficiente para constituir uma nova famnlia de argumentos, afirmada a partir do antagonismo dualista entre a sociedade e o Estado.

A primeira família de argumentos corresponde à antiga e surpreendentemente vital linhagem do jusnaturalismo ${ }^{7}$. Nela, a sociedade civil é introduzida, por oposição ao estado de natureza, como hipótese intermediária na reconstrução lógica das razões legítimas do surgimento do Estado. Mais: a sociedade civil é propriamente o Estado, ou seja, o único caminho passível de ser trilhado para resolver os dilemas inerentes ao estado de natureza. Por exemplo — para lembrar o discorrer clássico do Leviatan (1651) — o promissor direito natural a todas as coisas como eqüivalente mediato da guerra de todos contra todos. Em Hobbes existem razões e medos de peso para alguém ajuizado o suficiente não renunciar a seu direito natural, "Porém, num Estado civil onde existe um poder apto para constranger a quem - de outra forma - violaria sua palavra, tal temor não é mais razoável e, por essa razão, aquele que em virtude do pacto vê-se obrigado a cumprir primeiro, tem o dever de assim fazê-lo"8. Embora a partir de uma construção "civilizada" do estado de natureza, também Locke, no seu Segundo tratado sobre o governo (1690), reafirma a relação jusnaturalista de identidade entre a lei e a sociedade civil ao definir a última como uma sociedade com Estado: "Os que estão unidos em um corpo, tendo lei comum estabelecida e judicatura - para a qual apelar - com autoridade para decidir controvérsias e punir os ofensores, estão em sociedade civil uns com os outros; mas os que não têm essa apelação em comum, quero dizer, sohre a terra, ainda se encontram no estado de

duas versões amplas do argumento da sociedade civil: a primeira, cristalizada na obra de Tocqueville e herdeira de seus traços principais, e a segunda, organizada em torno àquilo que poder-se-ia chamar de argumento da nova sociedade civil; entretanto, o campo das teorias da sociedade civil dificilmente resulta passível de organização a partir de duas grandes famílias de argumentos.

${ }^{7}$ Os amplos consensos atuais em torno à problemática dos direitos humanos são tributários, sem dúvida, do arcabouço de argumentos jusnaturalistas. Seja dito de passagem, resulta surpreendente a escassa atenção que Jean Cohen e Andrew Arato (op. cit. pp. 87-89) dedicam a essa tradição no seu extenso trabalho - é claro que isso decorre de eles considerarem o jusnaturalismo como uma vertente não moderna de pensamento da sociedade civil.

8 Thomas Hobbes, Leviatan o la materia, forma y poder de una república eclesiástica y civil. p. 112 (grifo nosso). 
natureza, sendo cada um, onde não há outro, juiz para si e executor, o que constitui, conforme mostrei anteriormente, o estado perfeito de natureza" 9 .

A segunda famíia de argumentos também equaciona a sociedade civil em termos do Estado, porém, de forma mediata, como um importante patamar de universalização de relações sociais cujas insuficiências precisam e pressupõem uma instância superior de racionalização. Há inúmeras divergências em torno do sentido e as implicações da subsunção da sociedade civil ao Estado, e até sobre o fato de existir propriamente uma subsunção ou apenas subordinação legítima ou pura dominação; entretanto, é claro que, direta ou indiretamente, os diversos argumentos beberaram na mesma fonte: Hegel e sua Filosofia do direito (1821). Na elaboração da que fora a primeira teoria moderna da sociedade civil, ${ }^{10}$ o filósofo alemão introduziu um deslocamento duplo em face da tradição jusnaturalista - que na Alemanha contara com adeptos da envergadura de Kant. Em primeiro lugar, Hegel estava preocupado com a rudimentar analogia mercantil que, ao fazer do contrato o expediente para sair do estado de natureza e o garante da vida social, condenava a sociedade civil à lamentável condição da pura contingência. Enquanto o contrato permanece subordinado aos caprichos do arbítrio e da moralidade de cada um, a realização da sociedade civil, cuja "natureza é totalmente distinta e mais elevada" 1 , independe das vicissitudes individuais e se insere plenamente no mundo das instituições sociais — quer dizer, da eticidade ( $\$$ 182-256).

Além de elevar o estatuto da sociedade civil quanto à contingência do arbítrio individual e aos limitas da vida familiar, fez-se necessário, em segundo lugar, diferenciá-la do Estado. Na redefinição, a sociedade civil interage dirigida por fins egoísticos — sistema de necessidades ( $\$ 189-208$ ) - condicionados pela dependência multilateral em um sistema de instituições administrativas e direitos - policy e corporações ( $\S 230-256)$, e Judiciário ( $\$$ 209-229) —, definindo uma forma de uni-

9 John Locke, Segundo tratado sobre o governo - Ensaio relativo à verdadeira origem, extensäo e objetivo do governo civil. p. 67 (grifo nosso).

$10 \mathrm{Cf}$. Jean Cohen e Andrew Arato, op. cit. p. 91.

11 "(...) em época recente, os direitos do príncipe e do Estado têm sido considerados como objetos de contrato e sobre ele fundados, como coisa simplesmente comum da vontade e como algo decorrente do arbítrio dos associados em um Estado. Se, de um lado, há perspectivas diferentes, de outro, têm em comum o fato de terem deslocado as determinações da propriedade privada para uma esfera que devido a sua natureza é totalmente distinta e mais elevada". G. W. F. Hegel, Filosofía del derecho. § 75, p. 92. 
versalização ainda insuficiente, um Estado chamado por Hegel de externo, sem capacidade de impor custos ao conjunto da sociedade. ${ }^{12}$ Assim, o Estado político ou Estado interno aparece como única e última instância de harmonização e universalização - que inclui imposição — de interesses, superando e contendo dentro de si a sociedade civil. Eis o resultado do duplo deslocamento: uma teoria triádica da sociedade civil, na qual existe uma nítida diferença entre o mundo privado, familiar e de particulares isolados, o mundo institucional econômico e estatal da sociedade civil e o magno mundo político nacional e internacional do Estado.

A terceira família de argumentos da sociedade civil introduz mudança de substanciais conseqüências ao diferenciar definitivamente aquela do Estado. Isto implica não apenas diluir qualquer possibilidade de identidade entre a sociedade civil e o Estado — preocupação já presente em Hegel mediante seu duplo deslocamento -, mas em cancelar a relação de interioridade que fazia do Estado o âmbito da plena superação das divergências de interesses próprias das instituições da vida social. Do lado do "patrimônio reduzido" da sociedade civil permanecem, então, apenas as redes e hábitos de associação, cuja atividade participativa resulta fundamental tanto para a vitalidade de um regime democrático quanto para o desempenho do bom governo. Assim, nessa família de argumentos confere-se especial ênfase "na capacidade da vida associativa, em geral, e nos hábitos de associação, em particular, para fomentar modelos de civilidade nas ações dos cidadãos numa organização política democrática"13. Com efeito, para um herdeiro dessa tradição como Robert D. Putnam, a virtude principal da sociedade civil "reside em sua capacidade de socializar os participantes sob 'normas de reciprocidade' e 'confiança' que são componentes essenciais do 'capital social' necessário para a cooperação efetiva"'l4.

Subjaz na origem dessa família de argumentos a experiência histórica de uma sociedade na qual a gênese do Estado e a organização da vida comunitária foram processos paralelos - embora não por isso neces-

12 "O fim egoísta na sua realização, condicionado assim pela universalidade, estabelece um sistema de conexão universal pela qual a subsistência e o bem-estar do indivíduo e sua existência jurídica, imbricada com a subsistência, o bem-estar e o direito de todos, cimentamse sobre eles e apenas nessa dependência são reais e têm segurança. Esse sistema pode ser considerado como Estado externo, como estado da necessidade e do entendimento" .Ibid. $\$$ 183, p. 194 (grifo nosso).

13 Michael W. Foley e Bob Edwards, op. cit. p. 2

14 Ibid. p. 3 
sariamente harmônicos. É claro que a leitura clássica dessa experiência cristalizara-se mediante as inúmeras penadas de Alexis de Tocqueville: fora seu olhar sagaz, a colher observações cá e lá, que lhe permitira interpretar as lições projetadas por $A$ democracia na América (1835) para o futuro político da humanidade. São bem conhecidos seus receios perante a ameaça de uma forma inédita de escravidão, própria dos séculos democráticos, de um "despotismo benigno" decorrente da atomização individual, da extinção dos poderes secundários ou intermediários e da expansão e concentração do poder social no Estado. ${ }^{15}$ Entretanto, diferentemente das nações européias, onde a desigualdade social impunha a presença de um poder central particularmente forte, ${ }^{16}$ a história da América do Norte continha uma espécie de antídoto contra os perigos do "despotismo democrático", a saber, o uso irrestrito do direito de associação. ${ }^{17}$ Os interesses privados associados, ou seja, a sociedade civil, representam não apenas a única forma de resistência dos cidadãos ao poder central, mas, e isto é fundamental, uma condição do bom governo. ${ }^{18} \mathrm{De}$ forma aguda, o diagnóstico de Tocqueville mantém uma tensão — não uma simples oposição dicotômica - entre, de um lado, a necessária concentração do poder e suas conseqüências inerentemente perversas e, do outro, a plausível e inevitável vida social igualitária e livre, que permite o exercício entusiasta do direito de associação, e suas conseqüências também inerentemente perversas. Destarte, nessa família de argumentos a sociedade civil - que não é o Estado, nem um momento ou Estado inferior superado no Estado Nação - transforma seu estatuto político adquirindo o sentido de veicular a intervenção da sociedade no Estado ou, com maior precisão, de se opor e participar mediante as associações civis, no que tange aos interesses da sociedade, nas diversas instâncias governamentais.

\section{EXTERIORIDADE, SOCIEDADE CIVIL NORMATIVA E ESTADO}

No decorrer do século XX já foram escritas inúmeras páginas que, assumindo a perspectiva analítica da sociedade civil, têm se debruçado na

15 Alexis de Tocqueville, La democracia en América. pp. 632-635.

16 “....) o poder social deve ser sempre mais forte e o indivíduo mais débil num povo democrático, que tem atingido a igualdade mediante um longo e penoso trabalho social, do que numa sociedade democrática, onde desde sua origem os cidadãos têm sido sempre iguais". lbid. p. 620.

${ }^{17}$ Ibid. pp. 206-212. 
análise do Estado e da democracia contemporâneos e das possibilidades de sua transformação substantiva. $O$ itinerário desse debate precisaria incluir, dentre outras, a obra de autores tão diversos como Gramsci, Arendt, Schmitt, Koselleck, Kolakowski, Bobbio, Lefort, Luhman, Habermas, Putnam, Cohen, Arato, Keane e Mouffe. ${ }^{19}$ Contudo, a influência de suas obras no que diz respeito à reformulação do conceito da sociedade civil tem sido muito diferenciada. De fato, malgrado a interlocução própria dos campos teóricos, o uso mais difundido e quase consensual do conceito corresponde, hoje, ao modelo da nova sociedade civil, cuja paternidade resulta particularmente restrita. Tratase do extenso trabalho de Cohen e Arato que, a partir dos avanços extraídos mediante ampla revisão dos principais desenvolvimentos teóricos existentes e se apoiando no programa de pesquisa de Habermas - particularmente no âmago do da teoria da ação comunicativa ${ }^{20}$ — , redefiniu a sociedade civil de forma a sistematizar o crescente uso do termo nas última décadas, a repensar problemas históricos particulares e a possibilitar a pesquisa empírica.

O modelo da nova sociedade civil e as análises cabalmente por ele informadas não preservam qualquer parentesco próximo com as três grandes famílias de argumentos. Embora sua ascendência seja reconhecidamente marxista, há um afastamento de tal filiação em virtude das fortes dissonâncias produzidas por alguns princípios analíticos da obra de Marx, se combinados com uma teoria da sociedade civil como uma força democratizadora. Andrew Arato é explícito quando esclarece que "A recuperação do conceito de sociedade civil, há cerca de vinte anos, foi obra dos neomarxistas que criticavam o autoritarismo socialista e que, paralelamente, acabaram por derrubar um dos pressupostos básicos de Marx, razão pela qual se tornaram 'pós-marxistas'". $21 \mathrm{Na}$ verdade, o corpus teórico do pensador alemão pode-

18 "Os cidadãos dos Estados Unidos não têm qualquer superioridade uns sobre outros, nem se devem reciprocamente respeito ou obediência; eles administram unidos a justiça, governam o Estado e, em geral reúnem-se todos para discutir os negócios que influem no destino comum (...)". Ibid. p. 557.

19 A principal avaliação comparativa de alguns desses autores é a conhecida obra de Jean Cohen e Andrew Arato, op. cit. pp. 117-254 e 249-343. Para outras revisôes comparativas aprofundadas, embora de menor fôlego, cf. Nora Rabatnikof Maskivker, El espacio público: caracterizaciones y expectativas. pp. 73-267; e Adrián Gurza Lavalle, Estado, sociedad y medios - reivindicación de lo público. pp. 75-214.

20 Cf. Leonardo Avritzer, "Além da dicotomia Estado/Mercado - Habermas, Cohen e Arato". Novos Estudos, pp. 220-222; e Sérgio Costa, "Categoria analítica ou passe-partout políticonormativo: notas biográficas sobre o conceito de sociedade civil". $B I B, 43,1997$, pp. 8-9.

21 Andrew Arato, "Ascensão, declínio e reconstrução do conceito de sociedade civil Orientações para novas pesquisas". Revista Brasileira de Ciências Sociais, 27, 1995, p. 18. 
ria ser analisado como a fonte de uma quarta família de argumentos, se não diluísse a sociedade civil na economia política ao conceber a primeira como puro sistema de necessidades, como o universo infra-estrutural das relações econômicas - a partir de uma apropriação incompleta do desenvolvimento do conceito de Hegel. ${ }^{22}$ Assim, "(...) não é o Estado que condiciona e regula a sociedade civil, mas é esta que condiciona e regula o Estado; (...) portanto, a política e sua história devem explicar-se a partir das relações econômicas e seu desenvolvimento e não o inverso".23 Além do mais, a categoria de sociedade civil, decantada em torno ao problemático fulcro moderno da racionalidade legítima do poder, dificilmente poderia ocupar qualquer posição de alta hierarquia em um arcabouço teórico preocupado não com a lógica universalizadora do Estado nem com seus fundamentos legítimos, mas com sua crítica e aniquilação revolucionárias.

De fato, a eiaboração de uma teoria da sociedade civil para além dos puros vínculos egoísticos do mercado pressuporia sua inserção no marco maior ou de uma racionalização justificadora da constituição do Estado ou de uma teoria da democracia e, é claro, ambos os objetivos resultam alheios à compreensão cabal do pensamento de Marx. ${ }^{24}$ Não é fortuito que os desenvolvimentos teóricos da tradição marxista a constituírem o núcleo sólido do modelo da nova sociedade civil sejam fornecidos, precisamente, por dois autores que reassentaram a questão da legitimidade: de forma fundamental e quase exclusiva, como já foi dito, pelo programa de pesquisa de Habermas, cujos fundamentos exigiram a construção de um vínculo inerente entre a verdade e a legitimidade, ${ }^{25} \mathrm{e}$, de forma indireta e

\footnotetext{
22 Norberto Bobbio, op. cit. 45-56.

23 Friederich Engels, Contribuição à história da Liga dos Contunistas. Apud Karl Marx, La ideologia alemana. p. 7; a frase de Engels refere-se de forma resumida à posição de Marx em 1844, quando da redação dos Anais Franco-alemäes. Entretanto, a formulação clássica no que diz respeito à sociedade civil não pertence aos Anais, mas a um texto posterior: "(...) as relações jurídicas, assim como as formas de Estado, não podem ser explicadas por si próprias, nem pela chamada evolução geral do espírito humano, que se originam nas condições materiais de existência que Hegel, seguindo o exemplo dos ingleses e dos franceses do século XVIII, compreendia sob o nome de 'sociedade civil'; porém, a anatomia da sociedade tem de ser procurada na economia política". Karl Marx, Prefacio a la contribución a la crítica de la economia política. pp. 36-37.

24 Para uma análise das razōes pelas quais Marx abordou sistematicamente outros problemas que não os da democracia ou do arcabouço institucional do governo democrático, cf, a conhecida exposição de Norberto Bobbio, Qual Socialismo? Discussão de uma alternativa. pp. $21-35$ e $37-54$.

25 A questão da legitimidade foi assim equacionada pela primeira vez, com conseqüências muito relevantes para seu programa de pesquisa, em Jürgen Habermas, A crise de legitimaf̧āo
} 
bastante mediada, pela obra de Gramsci e sua reflexão sobre a hegemonia como uma combinação de coerção e consenso - isto é, a legitimidade. ${ }^{26}$ Contudo, e a despeito do risco de delir a sociedade civil na economia, existe em Marx um argumento contundente sobre a especificidade da relação entre aquela e o Estado: a aparente universalidade do Estado, como a instância de superação das desavenças de interesses, é possível apenas porque esse mundo da igualdade formal constitui-se como cisão do mundo real, regido pelo particularismo e pela iniqüidade. Ainda mais, o caráter irreconciliável e dilacerado da sociedade civil é a essência e o fundamento do Estado 27 - o que bem pode ser traduzido como o conhecido primado estrutural do econômico sobre o político. Assim, em Marx mantém-se entre o Estado e a sociedade uma relação de interioridade, embora ela permaneça oculta e apareça sob a forma da independência ou da exterioridade.

Até a aparição do novo modelo, o campo das formulações teóricas sobre a sociedade civil, povoado por bastos argumentos, manteve sua unidade e sua continuidade alicerçada numa premissa fundamental, a saber, o caráter absolutamente constitutivo do vínculo entre a sociedade e o Estado - equacionado com a introdução da sociedade civil como conceito que cristaliza a mediação entre ambos. A sociedade civil foi por isso definida ora como o Estado ou, melhor dizendo, como a sociedade com leis de observância universal; ora como a instância prévia à plena realização do Estado; ora como as associações civis a limitarem o poder central e veicularem a intervenção da sociedade no Estado; ora como a verdadeira matriz da dinâmica social e das feições políticas do Estado. Poder-se-ia dizer, de forma muito esquemática e correndo os riscos de toda simplificação, que a sociedade civil apresentou-se, então, como o momento do Estado, no Estado ou anterior ao Estado - seja na forma de fase inferior, seja na forma de fundamento estrutural —, o que fez com que ela — a sociedade civil - não pudesse ser concebida como um momento independente da constituição do perfil político do Estado.

Nesses termos, o modelo da nova sociedade civil carateriza-se pelo abandono da premissa fundamental sobre o caráter internamente constitutivo do vínculo entre a sociedade e o Estado, restabelecendo apenas

no capitalismo tardio (1973), pp. 121-140. Para os efeitos e posição dessa mudança conceitual no programa de pesquisa de Habermas cf. Adrián Gurza Lavalle, "A humildade do universal: Habermas no espelho de Rawls". Lua Nova 42, 1997, pp. 167-170.

26 Cf. Sérgio Costa, "Categoria analítica ou...". op. cit, pp. 8-9.

27 Cf. v. gr., Karl Marx e Friederich Engels, La ideologia... op. cit. pp. 35-38. 
uma relação de oposição externa entre eles. Com efeito, a polêmica novidade dessa nova sociedade civil reside na sua definição como um momento oposto ao Estado, sem qualquer liame ou intercâmbio conformativo que não seja dado a posteriori, isto é, apenas como decorrência do seu confronto. Nessa relação dicotomizada, o pólo axiológico positivo corresponde à sociedade civil, convertida em protagonista de um incessante conflito com o Estado, que, por sua vez, ocupa a posição do antagonista e o pólo de valor negativo. Não é gratuito que dois anos depois da publicação de Social theory and civil society e refletindo em torno aos problemas que permaneceram de pé, Arato tenha reavaliado, precisamente, algumas das dificuldades produzidas por essa dualização: "(...) no plano da Sociologia geral, é sem dúvida alguma questionável que uma coisa inexistente (a sociedade civil num regime totalitário) possa, apesar disso, contribuir para sua própria libertação". 28

Cabe salientar que em todos os argumentos examinados a sociedade civil encerrava interesses divergentes, quer fossem regulamentados e estabilizados na sua contraposição, quer fossem cabalmente harmonizados mediante sua ascensão à esfera universal do Estado ou defendidos na sua particularidade junto às instâncias administrativas governamentais ou até ocultos quanto ao seu caráter irreconciliável pela existência de uma instância ilusória de representação do interesse geral — o Estado. Já o novo modelo ungiu a sociedade civil de universalidade, despindo-a de seus particularismos e fazendo dela o espaço do interesse geral. ${ }^{29}$ A partir desses dois grandes traços, sua contraposição ao Estado e seu papel como portadora e transmissora do interesse geral, a sociedade civil adquire um perfil nebuloso no que diz respeito às feições daquilo que pode ou não ser incluído nela - visto que para se enquadrar nesses parâmetros é preciso se tratar de associações não-estatais e não-econômicas, de base voluntária e aparição mais ou menos espontânea, ${ }^{30}$ o que exclui sindicatos, partidos políticos, igrejas, cooperativas, universidades e um amplo leque de formas as mais variadas de organização.

\footnotetext{
28 Andrew Arato, “Ascensão, declínio...". op. cit., p. 19.

29 "O núcleo da sociedade civil é constituído por uma teia associativa que institucionaliza os discursos portadores de soluções para os problemas tangentes e questōes de interesse geral". Jürgen Habermas, Facticidad y Validez - Sobre el derecho y el Estado democrático de derecho en términos de teoria del discurso. P. 447.

30 Cf. ibid.
} 
A ambigüidade gerada pelo elenco de atributos esparsos de forma mais ou menos pura no imenso mundo das organizações seria um obstáculo praticamente inelutável, não fosse porque "(...) a primazia da coordenação da ação comunicativa no interior de uma multiplicidade de instituições corresponde ao fundamento da unidade da categoria chamada sociedade civil".31 O fundamental é, "Entretanto, [que] a unidade da sociedade civil só é óbvia quando considerada de uma perspectiva normativa". ${ }^{32}$ No cerne dessa inversão, que faz da sociedade civil um pólo antagônico definido de forma normativa, jaz um complexo problema cuja elucidação constitui um passo obrigatório para a crítica do modelo aqui examinado. Não se trata do despropósito de colocar em xeque o pensamento normativo, pois seu concurso resulta indispensável para se pensar criticamente. É claro que sua maior ou menor pertinência depende tanto de sua qualidade quanto do nível da reflexão no qual ele é colocado, introduzindo suas exigências perante a realidade. Neste caso, a atribuição de qualidades morais à sociedade civil, isto é, à teia autônoma de organizações que definem seu corpo, corre o risco de reentronizar exatamente aquilo que fora expulso do programa de pesquisa de Habermas, ${ }^{33}$ a saber, os atores e sujeitos fornecidos pela filosofia da consciência. Mas isso precisa de uma análise mais detida.

É consenso que a teoria da nova sociedade civil estabeleceu uma ponte com a obra de Habermas a partir da qual modelou seu conceito. A sociedade civil corresponde, assim, ao marco institucional do mundo da vida habermasiano, ${ }^{34}$ ou seja, àquela parte mobilizada e ubíqua da sociedade que, atrelada nas suas raízes à esfera privada, interage na esfera pública defensiva e ofensivamente na incerta salvaguarda do interesse geral. A despeito de certas nuanças, também parece ser consenso que a esfera pública e a sociedade civil são conceitos analiticamente diferenciados, ${ }^{35}$ embora complementares,

\footnotetext{
31 Andrew Arato, “Ascensão, declínio...”. op. cit., p. 21.

32 Ibid.

${ }^{33} \mathrm{Cf}$. Jürgen Habermas, The philosophical discourse of modernity - Twelve lectures. pp. 294326.

34 Jean Cohen e Andrew Arato, Civil society and... op. cit. pp. 428, 440, 495; cf. Leonardo Avritzer, "Além da dicotomia..." op. cit. pp. 220; e Sérgio Costa, "Categoria analítica ou..." op. cit. pp. 8-9.

35 Cf. Jürgen Habermas, Facticidad y Validez... op, cit. pp. 440-460; Leonardo Avritzer, "Diálogo y reflexividad: acerca de la relación entre esfera pública y medios de comunicación". Metapolítica 9, 1999, pp. 79-85; e Andrew Arato e Jean Cohen, "Esfera Pública y Sociedad Civil". Metapolitica 9, 1999, pp. 37-40.
} 
correspondendo, o primeiro, ao nível espacial ou estrutural da "(...) integração legalmente regulada de grupos, associações e movimentos (...)"36 perante o Estado e, o segundo, ao nível dinâmico da intervenção desses atores. Porém, parece pouco refletido o fato de os procedimentos analíticos próprios da esfera pública e, em geral, do programa de pesquisa de Habermas resultarem inadequados se incorporados e aplicados no modelo da nova sociedade civil. Aquilo que resulta plausível na universalidade olímpica das teorizações habermasianas dificilmente pode ser introduzido com sucesso no nível de uma teoria de menor alcance. A esfera pública pode desempenhar um papel normativo sem ser propriamente uma categoria normativa, porque, em Habermas, encontra-se alicerçada em uma estrutura ontológico-comunicativa que prescinde de qualquer conteúdo substantivo e de todo sujeito: "A soberania totalmente dispersa sequer se encarna nas cabeças de membros associados, mas - se de alguma forma ainda pode se falar em encarnação - apenas naquelas formas de comunicação carentes de sujeito que regulam o fluxo da formação discursiva de opinião e vontade (...)".37 Trata-se "(...) não de uma cidadania coletivamente capaz de ação, mas da institucionalização dos correspondentes procedimentos e pressupostos comunicativos (...)".38

Em consequiência, a formação de vontade sobre aquilo que, no processo da formação de opinião, foi determinado como interesse geral não pressupõe um sujeito definido normativamente, mas apenas o efeito de racionalização do poder e da vida social derivado de um agir comunicativamente estruturado. $\mathrm{O}$ fato de o modelo da nova sociedade civil incorporar os aportes habermasianos da teoria da ação comunicativa pareceria lhe emprestar certos alcances normativos pois, afinal, haveria uma forte afinidade conceitual e à sociedade civil caberia o papel de "(...) manter intactas as estruturas comunicativas do espaço da opinião pública" 39 ou esfera pública. Contudo, enquanto Habermas avalia o efeito racionalizador de estruturas de comunicação socialmente estabilizadas, o novo modelo põe logicamente a unidade e o sentido de uma sociedade civil definida de

\footnotetext{
36 Ibid. p. 39; para Habermas mantém-se a metáfora espacial, no entanto, ele não aceita para a esfera pública uma definição em termos institucionais, mas como uma “ (...) rede para comunicação de conteúdos e tomada de posições (...)". Jürgen Habermas, Facticidad y Validez... op. cit. p. 440.

37 Jürgen Habermas, "La soberania popular como procedimiento - Un concepto normativo de lo público". In Maria Herrera (coord.), Jürgen Habermas - Moralidad, ética y políica. Propuestas críticas.p. 53.

38 Jürgen Habermas, Facticidad y Validez... op. cit. p. 374.

39 Ibid. p. 450.
} 
forma normativa, isto é, repõe a antiga tradição do(s) ator(es) morais da transformação social. Trata-se, acima de tudo, da sociedade civil como um projeto político e, por isso, para Cohen e Arato, "O que é preciso é uma concepção da sociedade civil que possa refletir na essência das novas identidades coletivas e articular os termos dentro dos quais os projetos baseados em tais identidades podem contribuir para a emergência de sociedades mais livres e democráticas". 40

A grande e veloz influência do modelo da nova sociedade civil deriva-se, precisamente, da sua ênfase no fornecimento de um eixo de orientação para a ação política: "O notável êxito histórico da recuperação do conceito, da qual tive [Arato] a felicidade de participar, deveu-se ao fato de que ele prenunciava um nova estratégia dualista, radical, reformista ou revolucionária, de transformação da ditadura, observada primeiramente no Leste Europeu e, logo depois, na América Latina, para a qual convergiu e forneceu os elementos de uma compreensão intelectual". ${ }^{41}$ A lanterna bem intencionada da teoria da nova sociedade civil teve uma eficácia políticoprática excepcional e para tanto reconstruiu um modelo altamente simplificado da oposição, normativamente reforçada, entre a sociedade e o Estado. Assim, numa espécie de revezo salvífico, a sociedade civil como projeto político apaziguou o incômodo ocasionado pelo declínio das promissoras elaborações analíticas sobre os novos movimentos sociais 42 que, outrora dominantes, tinham ocupado por sua vez o espaço deixado pelo recuo das teorias sobre a luta de classes - de hegemonia inconteste até a década de 60.43

O modelo da nova sociedade civil foi particularmente bem sucedido no fornecimento de uma via de reflexão para o retorno do ator moral da transformação social, entretanto, as condições que fizeram possível tal êxito esgotaram-se ápós os processos de democratização. Hoje, pagando o custo de suas antigas virtudes simplificadoras, o modelo da nova sociedade civil não apenas perdeu pertinência nas tarefas da apreensão analítica ou de orientação prática, mas se defronta com o caráter problemático de três de suas principais tendências: em primeiro lugar, tem resultado paradoxalmente consoante com tendências conservadoras atuais como a retração do

40 Jean Cohen e Andrew Arato, Civil society and... op. cit. pp. 421.

41 Andrew Arato, “Ascensão, declínio...". op. cit., p. 19.

42 Cf. v. gr. Eder Sader, Quando novos personagens entram em cena. Pp. 25-60.

43 Cf. Maria da Glória Gohn, Teoria dos movinentos sociais - Paradigmas clássicos e contemporâneos. pp. 121-240. 
Estado; ${ }^{44}$ em segundo lugar, e diante da desproteção social de amplas camadas da população, tem favorecido o desprezo pelas instituições do sistema político; ${ }^{45}$ e por último, tem se convertido no principal marco de referência da exponencial multiplicação de ONGs, ${ }^{46}$ que parecem estar consolidando um setor de serviços de intermediação social afastado das intenções normativa do modelo.

ADRIÁN GURZA LAVALLE é professor na Universidade Nacional Autónoma - UNAM e na Universidad Iberoamericana, ambas no México, e doutorando em Ciência Política na USP. Publicou em Lua Nova "A humildade do universal: Habermas no espelho de Rawls" (n $\left.{ }^{\circ} 42,1997\right)$

44 Cf. Sergio Costa, "Esfera pública, redescoberta da sociedade civil e movimentos sociais no Brasil - Uma abordagem tentativa". Novos Estudos, 38, 1994; e James Petras e Sonia ArellanoLópez, "A ambígua ajuda das ONGs na Bolívia". Cadernos do CEAS, n 146, pp. 57-67.

45 Cf. Ricardo Toledo Neder, "As ONGs na reconstrução da sociedade civil no Brasil". Seminário Internacional Sociedade, Reforma e Estado, pp. 4-8.; e Adrián Gurza Lavalle, "Dos paradojas de la sociedad civil mexicana". Etcétera 44, 1995.

46 Cf. Maria da Glória Gohn, Teoria dos Movimentos... op. cit. pp. 295-325; e Ana Amélia da Silva, "Do privado para o público - ONGs e os desafios da consolidação democrática", Cadernos do CEAS, $\mathrm{n}^{\circ} 146$ pp. 36-45. 


\section{CRÍTICA AO MODELO DA NOVA SOCIEDADE CIVIL}

O modelo da "nova sociedade civil" é submetido a uma análise crítica mediante uma retomada dos fundamentos da idéia clássica de sociedade civil e um exame das conseqüências (infelizes) da ruptura com essa tradição conceitual.

\section{THE MODEL OF THE NEW} CIVIL SOCIETY: A CRITIQUE

The model of the "new civil society" is subjected to a critical 
analysis through a resumption of the foundations of the classical idea of civil society and an examination of the (unhappy) consequences of the breach with that conceptual tradition. 